American Journal of Economics and Business Administration 3 (3): 552-559, 2011

ISSN 1945-5488

(C) 2011 Science Publications

\title{
Extending the Technology Acceptance Model to Account for Social Influence, Trust and Integration for Pervasive Computing Environment: A Case Study in University Industry
}

\author{
${ }^{1}$ Farahwahida Mohd, ${ }^{1}$ Faudzi Ahmad, ${ }^{2}$ Norsila Samsudin and ${ }^{3}$ Suhizaz Sudin \\ ${ }^{1}$ Faculty of Industrial Information Technology, \\ ${ }^{2}$ Faculty of Social Science and Industrial Studies, \\ University Industry Selangor, 45600 Bestari Jaya Kuala Selangor \\ ${ }^{3}$ Faculty of Engineering University Malaysia Perlis, 02600 Arau, Perlis
}

\begin{abstract}
Problem statement: The aims of this study are to develop ubiquitous computing environment using Bluetooth (UCEB) and measure the validity and reliability on in order to support student admission services in University Industry Selangor (UNISEL). Approach: This study is based on the descriptive survey research using revised Technology Acceptance Model (TAM), known as Pervasive Technology Acceptance Model (PTAM). Results: This research involved all the aspects of PTAM which are namely perceived usefulness, perceived ease of use, social influence, trust, integration, attitude, behavioural intention and actual use towards using the UCEB. A total of 111 respondents were selected as a sample for this study. This research is also conducted on the same respondents to find out the user acceptance on UCEB to support student admission services. Conclusion/Recommendations: The respondents were the academic committees consist of students, academicians and non-academician of UNISEL. A questionnaire was used to collect information from the respondents based on likert scale to measures the extent to which a person agrees or disagrees with the question. The quantitative data were analyzed using SPSS system to produce statistical inference for Pearson correlation test.
\end{abstract}

Key words: Technology Acceptance Model (TAM), pervasive computing environment, social influence, industry Selangor, Pervasive Technology Acceptance Model (PTAM), UCEB

\section{INTRODUCTION}

The whole world is going mobile. Phones, computers and media devices now fit in our pockets and can connect us to a variety of information sources and enable communication nearly everywhere we go. There is considerable interest in exploiting the almost universal appeal and abundance of these technologies for the educational use. With respect to the technologies, 'mobile' generally means portable and personal, like mobile computers, including devices such as handheld computers, mobile gaming devices and cell phones.

Handheld computers, the devices used in this study, are roughly the size of a small calculator, easily portable, resemble computers in that they have an operating system and software applications and often depend on a touch screen for user input.

Initial evaluation reports and academic research have yielded baseline data that indicate that a large majority of teachers across subject areas considers handhelds to be effective tools in the classroom and believes that they can have a positive impact on student learning, especially because it is more realistic now than ever to attain a 1:1 computer to student ratio (Soloway et al., 2001; Vahey and Crawford, 2002; Van Hover et al., 2006; Champadaeng, 2010; Po-Klin et al., 2010; D'Silva et al., 2010 and Azizi et al., 2010).

Problem statement: Walking around any college campus today, the acceptance and usage of handheld and wireless technology is readily apparent. Student, academician and administrative staff use these devices to talk, message (or even see) whom they want, what they want and when they want. Currently, most of mobile devices are equipped with wireless technology (Bluetooth). Bluetooth is a wireless technology specification designed to enable wireless communication between small devices like laptops, PDAs, mobile phones and others.

Corresponding Author: Farahwahida Mohd, Faculty of Industrial Information Technology, University Industry Selangor, 5600 Bestari Jaya Kuala Selangor 
But despite the widespread acceptance of the Bluetooth technology, handheld and wireless technology has barely made a dent in classroom, lecturer room and administration office room. This technology is supposed to help in supporting academic administrative services such as announcement of class cancellations, notice of pre-registration subjects, called for meeting and others through the sending of message to the mobile devices which equipped with Bluetooth technology with no cost involved, during they are in the campus.

Many university teachers, uncomfortable with their own use of technology, feel somewhat threatened by these new forms of communication knowing that in many cases their students are more technologycompetent than they are themselves. Peters (2005) found that teachers, who may be very comfortable using computers, are not so familiar with mobile technologies-unlike many of their students.

From the observation, many students today are competent with ubiquitous technologies and that for many they play an important part in their daily social networking. The facility with which these small and pervasive technologies are used implies that they have a great deal of potential to be used in higher education. However, for many teachers it is easier to prohibit the use of these 'disruptive' technologies than to risk the illicit use of communication methods that they themselves are unable to understand or detect in use Mobiles fuel rise in cheating, (Bower and Christensen, 1995).

The risk for university teachers is that they may become increasingly alienated from many of the students they teach. The educational and sociological implications of these technologies are significant for teachers, not only for the need to understand the way students communicate, but for understanding the 'speeding up and intensification of system environment interactions' (Geser, 2004) that extends to the university context.

Despite the significant potential of mobile technologies to be used as powerful learning tools in higher education, their current use appears to be predominantly within a didactic; teacher centered paradigm, rather than a more constructivist environment. It can be argued that the current use of mobile devices in higher education (essentially content delivery) is pedagogically regressive. Their adoption is following a typical pattern where educators revert to old pedagogies as they come to terms with the capabilities of new technologies, referred to by Mioduser (1998) as 'one step forward for the technology, two steps back for the pedagogy' (p. 758). Adopting more recent theories of learning has the potential to exploit the affordances of the technologies in more valuable ways. Patten et al.
(2006) argue that the benefits of mobile learning can be gained, through collaborative, contextual, constructionist and constructivist learning environments. Authentic learning environments in higher education typically involve these characteristics (Herrington and Herrington, 2006).

This studying intends to examine the type of responses of the development of ubiquitous computing environment using Bluetooth to support learning in higher education. The survey method used in this study is an adaptation of the proposed extended on Pervasive Technology Acceptance Model (PTAM) by the researcher. In addition, this study is also focused on the acceptance of the academic community on using admission system using Bluetooth, its impact and status in comparison with other types of student admission system such as non-online(paper-based) and online (internet based) system. The members of the academic community in this research that will be the respondents of the study, refers to students, academic advisor and academic administrator in higher institution.

Pervasive computing: Pervasive computing embeds computing and information technologies into our environments by integrating them seamlessly into our everyday live. For over fifteen years, there has been study on novel technologies, infrastructures and applications under the heading of pervasive computing. While design has flourished in this domain resulting in entirely new areas such as calm technology, tangible computing and context-aware computing, evaluation of pervasive computing has struggled because of the inherent challenges posed by evaluating systems that are designed to be woven into the fabric of our everyday lives. Traditional evaluation techniques such as laboratory studies allow researchers to study and refine specific aspects of a design (such as an interface), but are not satisfactory for evaluating a technology's actual use in real life over time. In a laboratory, it is impossible to reproduce the richness of everyday life where unexpected events occur that can affect a person's interaction with a particular system. For example, when evaluating a system that automatically turns off a cell phone ringer depending on the context of the receiver, it is difficult to reproduce all factors that would affect a user's experience with the system, such as who is calling, why they are calling, what the receiver is doing, the other people in the vicinity.

To compensate for these problems, many researchers have turned to in-situ evaluation, where participants interact with the system during their normal lives over a period of time. Researchers utilize techniques such as experience sampling, cultural probes, observations, recall diaries, logs, questionnaires and interviews to obtain both qualitative and quantitative data about user experiences. In-situ 
evaluations tend to be resource intensive and of short duration (i.e., a few days or weeks). Indeed, many insitu studies utilize prototypes that are difficult to deploy for any length of time because portions of the system rely on non-existent infrastructure and must be simulated.

While both laboratory and in-situ studies provide valuable information during the design phase, neither currently provides insight into user acceptance and usage after the initial novelty wears off. Since the majority of proposed pervasive computing applications rely heavily on infrastructure that is not yet widely available, understanding long-term usage and acceptance is of utmost importance for determining if a technology/application is worth the required investment. Yet performing such an evaluation is difficult before the necessary infrastructure is available. The problem, then, is circular, requiring an evaluation to justify the necessary infrastructure investment and requiring the infrastructure to perform such an evaluation. Thus, a technique for predicting long-term usage after minimal exposure to a prototype system is needed to help direct researchers and industry towards those technologies with the most chance of gaining user acceptance.

Origins of technology acceptance model: Research into factors that predict Information Technology (IT) acceptance has received much attention because a major goal for many organizations is IT adoption and use (Money and Turner, 2004). The Technology Acceptance Model (TAM) is one such research model. Fred Davis developed TAM in the mid-1980s under contract with IBM Canada to evaluate the market potential and product development for emerging personal computer-based applications in the areas of multi-media, image processing and pen-based computing (Davis and Venkatesh, 1996). TAM is specifically designed to study IT-adoption and use and to predict and explain user acceptance of information technologies (Davis, 1993; Morris and Dillon, 1997). With TAM, researchers and practitioners can identify why a particular system may be unacceptable to the users and pursue appropriate corrective steps (Davis et al., 1989).

TAM has origins in the Theory of Reasoned Action (TRA), articulated (Fishbein and Ajzen 1975; Davis, 1993; Davis et al., 1989; Morris and Dillon, 1997). TRA is a model from social psychology, which is concerned with the determinants of consciously intended behaviours. TRA postulates that intentions to perform behaviour are a function of two basic determinants, one personal (attitude toward the behaviour) and the other reflecting social influence (subjective norms). Subjective norms are defined as the person's beliefs that specific individuals or groups approve or disapprove of performing the behaviour .TRA posits that people would perform a specific behaviour such as using computers, if they believe that it would lead to positive outcomes associated with using them. The behavioural intentions to use actually lead to actual system usage.

TAM has deep roots from a wide variety of theories such as the adoption of innovations, the costbenefit paradigm, expectancy theory and self-efficacy theory (Davis, 1989). The main goal of TAM is to provide an explanation of the determinants of computer acceptance and user behaviour across a broad range of end-user computing technologies and user populations (Davis, 1989; Davis, 1993; Davis et al., 1989). Original Technology Acceptance Model (TAM) posits that system design characteristics, quality of the system and training are among the external stimuli (variables) about which the user formed certain cognitive responses (Davis, 1993; Davis et al., 1989; Davis and Venkatesh, 1996). These responses are perceived usefulness and perceived ease of use of the system; and they are of primary importance and relevance for computer acceptance behaviours (Davis et al., 1989):

Perceived Usefulness (PU) is defined as the prospective user's subjective probability that using a specific application system will increase his or her job performance within an organizational context.

Perceived Ease Of Use (PEOU) refers to the degree to which the prospective user expects the target system to be free of effort.

Further, PEOU also has a causal effect on PU and factor analyses suggest that PU and PEOU are statistically distinct dimensions (Davis et al., 1989). The two variables PU and PEOU are, in turn, predicted to be linked to the affective response that is the Attitude (A) toward the use of the system and to Behavioural Intention (BI) and ultimately the actual user behaviour: Use of the system or rejection of the system (Davis et al., 1989). In addition, TAM also proposes a direct relationship between perceived usefulness and the behavioural intention to use (Morris and Dillon, 1997). System acceptance is defined by researchers as the potential user's predisposition toward personally using a specific system and system acceptance leads to system usage (Davis, 1993; Davis et al., 1989; Morris and Dillon, 1997). The ultimate objective of TAM is to measure and explain the system usage behaviour. (Davis et al., 1989). TAM posits that the influences of external stimuli are mediated through PU, PEOU and BI leading to performance of the behaviour: Actual 
system usage. Figure 1 for a visual representation of Davis (1989) TAM.

The causal chain linking external variables to actual use via the mediating variables namely perceived ease of use, perceived usefulness, attitude toward using and behavioural intention to use.

\section{Revised technology acceptance:}

Model: Pervasive Technology Acceptance Model (PTAM): With technologies becoming pervasive in our lives, both at study and at play, there is a need to extend technology acceptance models to account for this broader domain and user group. Pervasive computing moves away from the traditional desktop model of computing towards having technology embedded in the environment. Pervasive computing environments differ significantly from traditional workplace and academic settings in several ways: studied in other user acceptance models. The constructs have not previously been studied in a model (Fig. 2).

Social influence: Kelman's tudy of social influence was motivated by his interest in understanding the changes brought about in individuals' attitude by external inputs, such as information communicated to them. Specifically, his research attempted to understand if the change in attitude resulting from external stimuli was a temporary superficial change or a more lasting change that became integrated in the person's value system. He suggested that changes in attitudes and actions produced by social influences may occur at different "levels." In his view, the nature or level of changes that took place correspond to differences in the process whereby the individual accepts influence (or "conforms"). In other words, the underlying processes in which an individual engages when he adopts induced behaviour may be different, even though the resulting overt behaviour may appear the same.

Kelman distinguished between three different processes of social influence that affect individual behaviour: Compliance, identification and internalization. Compliance: When an individual adopts the induced behaviour not because she believes in its content but with the expectation of gaining rewards or avoiding punishments. Identification: when an individual accepts influence because she wants to establish or maintain a satisfying self-defining relationship to another person or group. Internalization: When an individual accepts influence because it is congruent with her value system.

Trust: Pervasive computing introduces an entirely new set of issues related to trust. First, pervasive computing environments often gather very intimate and personal data about its users. Indeed, many pervasive computing applications rely on gathering information about a user's physical and social context. Trusting the system to keep that information confidential and not to abuse it is an aspect of trust that must now come to the fore.

Second, the applications studied in the MIS domain have been relatively simple, static applications that behave according to users' expectations (once trained). Many pervasive computing applications, however, attempt to tailor their behaviour based on the context of the user and physical environment, resulting in behaviour that is not always predictable. An application that does not behave as a user expects causes the user to believe the application is not functioning properly. Thus, the notion of trusting an application to behave a certain way may play into user acceptance.

Integration: Pervasive technologies are no longer situated on the desk, but are embedded in the environment around us requiring interactions as we go about our daily lives. It is essential for a model to account for how well the technology is integrated into our lives. A person may reject a technology if it unduly distracts from or interferes with their other activities.

Research design: The research uses two phases in doing this research. The first phase is the development of Ubiquitous Computing Environment using Bluetooth (UCEB). This new system will be set up in selected place in the UNISEL. The second phase of this research is survey on this system implementation.

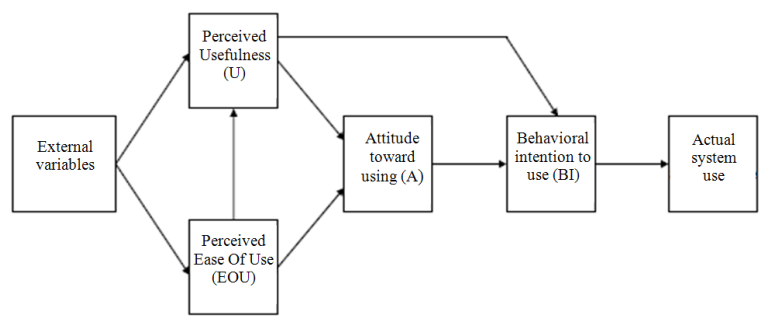

Fig. 1: Original technology acceptance model

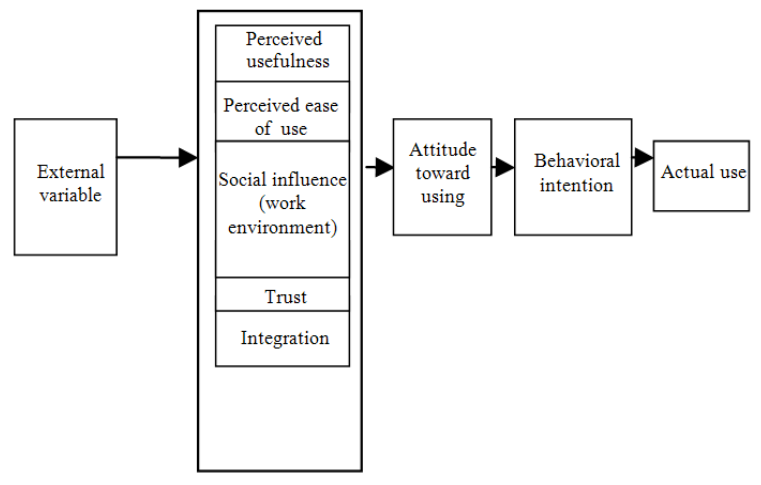

Fig. 2: Proposed pervasive technology acceptance model 
This research is based on the descriptive survey research. Meaning that researcher need the information from the people. The population chosen for this study is members of the academic community who are involve in student admission system. However, the researcher has chosen the University Industry Selangor (UNISEL) as the target population for the study. This is due to the fact that from the researcher's observation, this institution has an online student admission system compare to any other institution. Besides that, the reason why this institution are chose is simply because the researcher is actually teaching in this institution and therefore knows the institutions well.

In order to obtained information for this study, a questionnaire was used. The questionnaire will be distributed to all respondents concerned through their respective lecturer who is academic advisor. The set of questionnaires will be delivered personally by the researcher to all the head of faculty so that these questionnaires can then be distributed to all the respondents through their respective academic advisors. Each respondent is given one week's grace to complete these questionnaires. Upon the estimated time frame, the researcher will personally collect all the questionnaires that have been sent out. This done to simply make sure that all the questionnaires were returned accordingly and within the stipulated time frame.

A total number of 110 respondents were selected as a sample. In addition to this, an experimental research is conducted on the same respondents to find out the user acceptance on UCEB to support student admission services. The respondents were the academic committee. The academic committees are student, academician and non academician in UNISEL which have the handheld devices embedded with the Bluetooth technology. The responses from the respondents were very good. The researcher received $90 \%$ responses from the respondents.

\section{MATERIALS AND METHODS}

The research is held in a lecture room with all respondents having Bluetooth phone (Fig. 3). The objectives of this research are to tested the efficiency of Bluetooth technology to transfer data (an analysis on transmission rate while delivering text message, images and audio clip) and how this technology can support learning in UNISEL (the guideline on how to applying Bluetooth technology in learning). This experiment is also to familiarize the respondent with the Bluetooth application

The following Fig. 3 is illustrated the Bluetooth wireless range in classroom. There are server (embedded with Bluetooth device) interacting with the student which having the hand phone which embedded with Bluetooth.

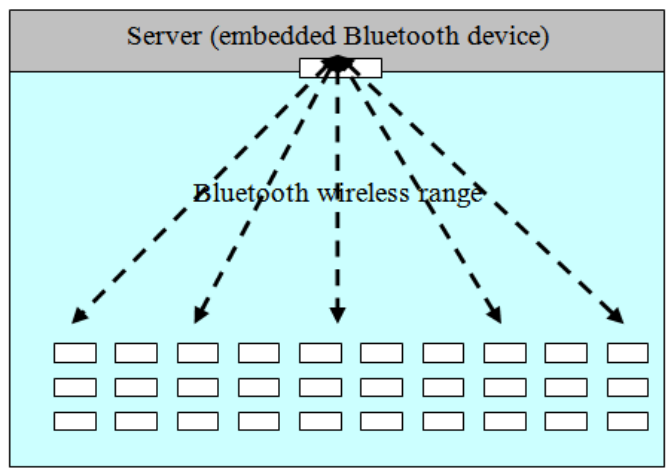

Fig. 3: Bluetooth wireless range

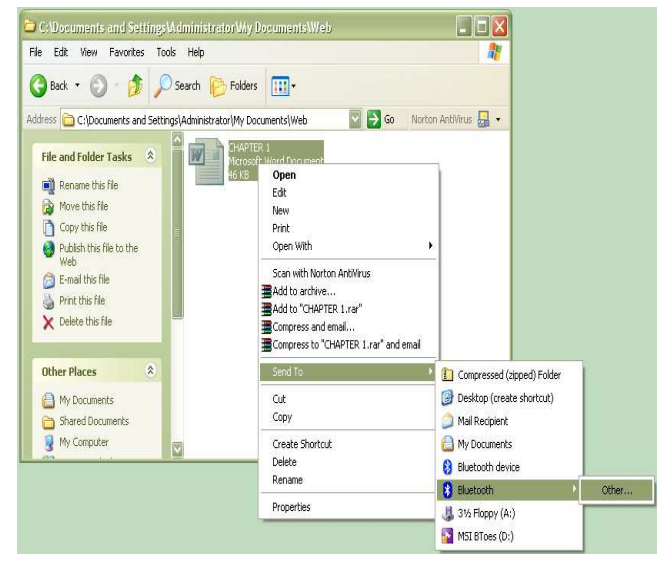

Fig. 4: Send the data

Guideline to applying Bluetooth Technology in Learning:

Sending data from Server to Bluetooth Phone: Before we start, there are some preparations that we have to do:

Step 1: Prepare the equipment.

We must prepare the equipment such as, laptop, external Bluetooth and software to install the external Bluetooth on the laptop.

Step 2: Attach the Bluetooth device to the USB port and install the software in order to using external Bluetooth on laptop.

Step 3: Sending the data:

- Choose a file. Right click and then click Send To, go to Bluetooth and click Other if this is the first time being used

- Figure 4 is illustrate the process of sending data

- Select a device and the click Ok. Before then, the computer will search for devices 


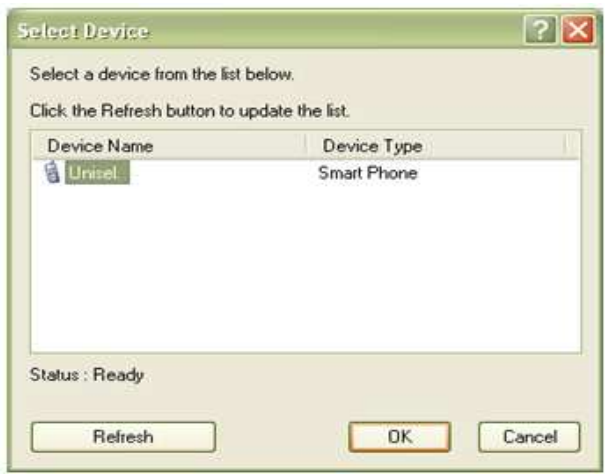

Fig. 5: Select the device

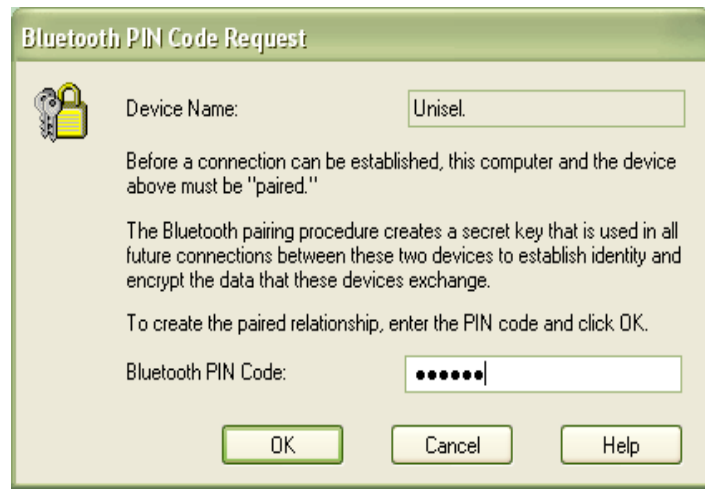

Fig. 6: Bluetooth PIN CODE request

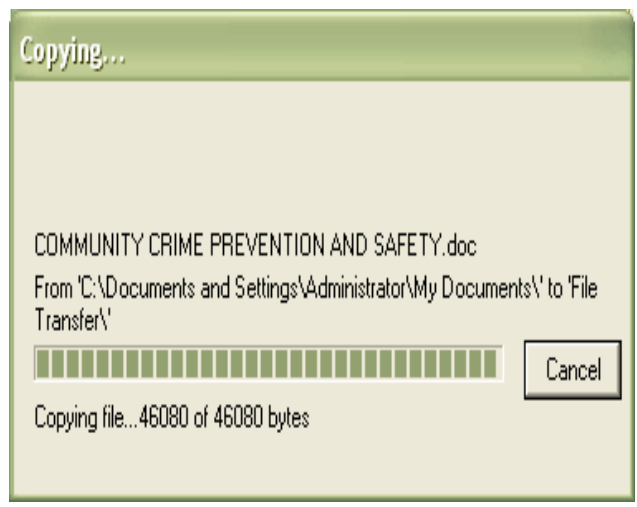

Fig. 7: Data sent

- Bluetooth PIN CODE request

- The data has been sent to Smart Phones or other external Bluetooth devices

Sending data from Bluetooth phone to server: Before we start, there are some preparations that we have to do.

Step 1: Prepare the equipment.
Make sure your hand phone is embedded with Bluetooth technology and have software to create messages such as Notes and Recorder for audio clip. Then on the Bluetooth signal on your hand phone Fig. 5-7.

Step 2: Create your text message at Notes or open your sound clip in Recoder.

Step 3: After you create your text message or open your sound clip, click Options to send the data via Bluetooth. (These steps may vary; depend on the type/model of hand phone).

Step 4: Select the server name, for example "Server" and your data will be submitted to the server

\section{RESULT AND DISCUSSION}

Correlation is often called a vicariate correlation to designate a simple correlation between two variables, as frequently observed in multiple regression analysis or structural equation modelling. A correlation is also frequently called the Pearson product-moment correlation or the Pearson. According to Karl S. Pearson has credited on the assumption that two variables involved are approximately normally distributed, the formula often performs well even when assumptions of normality are violated or when one of the variable is discrete. The Pearson correlation analysis is used to analyse the relationship between the variables as shown on the Table 1 .

The variables include Score A that there will be a positive relationship in perceived usefulness towards using the system, Score B that there will be a positive relationship in perceived ease of use towards using the system, Score $\mathrm{C}$ that there will be a positive relationship in social influence towards using the system, Score D that there will be a positive relationship in trust towards using the system, Score E that there will be a positive relationship in integration towards using the system, Score F that there will be a positive relationship in behavioural intention towards using the system, Score $G$ that there will be a positive relationship in attitude towards using the system and finally Score $\mathrm{H}$ that there will be a positive relationship in actual use towards using the system.

According to the correlation analysis, it is found that Score A perceived usefulness towards using the system has a positive relationship between Score B that is perceived ease of use towards using the system, Score $\mathrm{C}$ that is social influence towards using the system and Score $\mathrm{F}$ that is behavioural intention towards using the system at $1 \%$ significant level. 
Am. J. of Economics and Business Administration 3 (3): 552-559, 2011

Table 1: Correlation matrixes between variables in score a, b, c, d, e, f and $\mathrm{g}$

\begin{tabular}{|c|c|c|c|c|c|c|c|c|}
\hline & $\begin{array}{l}\text { Score A, } \\
\text { perceive } \\
\text { usefulness }\end{array}$ & $\begin{array}{l}\text { Score B, } \\
\text { perceive } \\
\text { ease of Use }\end{array}$ & $\begin{array}{l}\text { Score C, } \\
\text { social } \\
\text { influence }\end{array}$ & $\begin{array}{l}\text { Score D, } \\
\text { trust }\end{array}$ & $\begin{array}{l}\text { Score E, } \\
\text { integration }\end{array}$ & $\begin{array}{l}\text { Score F, } \\
\text { behavioral } \\
\text { intention }\end{array}$ & $\begin{array}{l}\text { Score G, } \\
\text { attitude }\end{array}$ & $\begin{array}{l}\text { Score } \mathrm{H} \text {, } \\
\text { actual use }\end{array}$ \\
\hline Score A, perceive usefulness & 1.000 & & & & & & & \\
\hline Score B, perceive Ease of Use & $0.402 * *$ & 1.000 & & & & & & \\
\hline Score C, social influence & $0.294 * *$ & $0.385^{* *} *$ & 1.000 & & & & & \\
\hline Score $\mathrm{D}$, trust & 0.148 & $0.249 * *$ & 0.142 & 1.000 & & & & \\
\hline Score $\mathrm{E}$, integration & $0.203^{*}$ & $0.280 * *$ & $0.555^{* * *}$ & 0.181 & 1.000 & & & \\
\hline Score $\mathrm{F}$, behavioral intention & $0.284 * *$ & $0.230 *$ & $0.036^{* * *}$ & 0.180 & $0.206^{*}$ & 1.000 & & \\
\hline Score $\mathrm{G}$, attitude & 0.052 & 0.133 & 0.167 & 0.083 & 0.102 & 0.041 & 1.000 & \\
\hline Score $\mathrm{H}$, actual use & -0.096 & $-0.187 *$ & -0.085 & 0.048 & -0.169 & 0.027 & 0.008 & 1 \\
\hline
\end{tabular}

(**): Correlation is significant at the 0.01 level; (*): Correlation is significant at the level 0.05 level

Whereas Score A has a positive correlation with Score $\mathrm{E}$ that is integration towards using the system at significant level of $5 \%$. Score D that is trust towards using the system and Score $\mathrm{G}$ that is attitude towards using the system has a weak positive correlation with Score $\mathrm{A}$ and finally Score $\mathrm{H}$ that is the actual use towards using the system has a weak negative relationship towards Score A perceived usefulness.

Among all the factors that are being tested on the relationship towards perceived usefulness of using the system, we identify that perceived ease of use has strongest association with perceived usefulness towards using the system that is $40.2 \%$ as compared to social influence $29.4 \%$ and behavioural intention $28.4 \%$.

Test on association with Score B perceived ease of use, it is found that Score B has a positive correlation with factors such as Score $\mathrm{C}$ social influence towards using the system $38.5 \%$, Score D trust towards using the system $24.9 \%$ and Score E integration towards using the system $28 \%$ at alpha of $1 \%$. Score $\mathrm{F}$ that is behavioural intention towards using the system, has a positive correlation with Score $\mathrm{B}$ while Score $\mathrm{H}$ that is the actual use towards using the system has a weak negative correlation at 5\% level of significant. Score $G$ that there will be a positive relationship in attitude towards using the system and finally Score $\mathrm{H}$ that there will be a positive relationship in actual use towards using the system.

When it comes to the relationship between Score C Social Influence and Score $\mathrm{E}$ that is integration towards using the system, it is found that there is a strong positive correlation $55.5 \%$ and Score $\mathrm{F}$ that is behavioural intention towards using the system $3.6 \%$ significant at $1 \%$, Score D trust towards using the system and Score G attitude towards using the system has a positive relationship with Score $\mathrm{C}$ and finally Score $\mathrm{H}$ the actual use towards using the system has a weak negative correlation with Score C Score D that is trust towards using the system has a weak positive relationship with Score E integration towards using the system, Score F the behavioural intention towards using the system, Score $\mathrm{G}$ the attitude towards using the system and Score $\mathrm{H}$ the actual use towards using the system.
As for Score $\mathrm{E}$ the integration towards using the system is significantly correlated with Score F the behavioural intention at $5 \%$ level. Score G the attitude towards using the system and Score $\mathrm{H}$ the actual use towards using the system has a weak positive and weak negative relationship respectively with Score E.

Score $F$ the behavioural intention towards using the system has a weak positive relationship with Score $\mathrm{G}$, attitude using the system and Score $\mathrm{H}$ the actual use towards using the system.

Last but not least, Score $G$ which is the attitude towards using the system also has a weak positive correlation against Score $\mathrm{H}$ the actual use towards using the system.

\section{CONCLUSION}

There is no doubt that technological change brings about social change. It is obviously that computers appear to be everywhere today. By examining the Pearson correlation, it is found that social influence has the highest value in correlation when it relates to the integration towards using the system that is 55.5 at $1 \%$ significant level. There is a positive relationship as well between perceived usefulness and perceived ease of use towards using the system, 40.2\%. The third highest value in relationship that is $38.5 \%$ is between perceived ease of use towards using the system and social influence in using the system. With these results, we can conclude that computer acceptance and user behaviour across a broad range of end-user computing technologies and user populations has a greater impact when it comes to the relationship with social influence.

\section{REFERENCES}

Azizi, B., J.F. Hosseini, M. Hosseini and M. Mirdamadi, 2010. Factors influencing the development of entrepreneurial education in iran's applied-scientific educational centers for agriculture. Am. J. Agric. Biol. Sci., 5: 77-83. DOI: 10.3844/ajabssp.2010.77.83. 
Bower, J.L. and C.M. Christensen, 1995. Disruptive technologies: Catching the Wave. 1st Edn., Harvard Business School Pub., Boston, pp: 11.

Champadaeng, S., 2010. The role of molam in solving social problems. J. Soc. Sci., 6: 365-368. DOI: 10.3844 jssp.2010.365.368.

Davis, F.D. and V. Venkatesh, 1996. A critical assessment of potential measurement biases in the technology acceptance model: three experiments. Int. J. Hum. Comput. Stud., 45: 19-45. DOI: 10.1006/IJHC.1996.0040

Davis, F.D., 1989. Perceived usefulness, perceived ease of use and user acceptance of information technology. MIS Q., 13: 319-340. DOI: $10.2307 / 249008$

Davis, F.D., 1993. User acceptance of information technology: system characteristics, user perceptions and behavioral impacts. Int. $\mathrm{J}$. Man-Mach. Stud., 38: 475-487. DOI: 10.1006/IMMS.1993.1022

Davis, F.D., R.P. Bagozzi and P.R. Warshaw, 1989. User acceptance of computer technology: A comparison of two theoretical models. Manage. Sci., 35: 982-1003. DOI: 10.1287/MNSC.35.8.982

D'Silva, J.L., H.A.M. Shaffril, J. Uli and B.A. Samah, 2010. Socio-Demography factors that influence youth attitude towards contract farming. Am. J. Applied Sci., 7: 603-608. DOI: 10.3844/ajassp.2010.603.608.

Fishbein, M. and I. Ajzen, 1975. Belief, Attitude Intention and Behaviour: An Introduction to Theory and Research. 1st Edn., Addison-Wesley Pub. Co., Reading, MA, ISBN: 0201020890, pp: 578.
Geser, H., 2004. Toward a sociological theory of the mobile phone. University of Zurich.

Herrington, A. and J. Herrington, 2006. Authentic Learning Environments in Higher Education. 1st Edn., Information Science Pub., Hershey, pp: 321.

Mioduser, D., 1998. Web-based Learning Environments: Current States and Emerging Trends. Tel-Aviv University, Tel-Aviv, pp: 40.

Morris, M.G. and A. Dillon, 1997. How user perceptions influence software use. Software, IEEE, 14: 58-65. DOI: 10.1109/52.595956

Patten, B., I.A. Sanchez and B. Tangney, 2006. Designing collaborative, constructionist and contextual applications for handheld devices. Comput. Educ., 46: 294-308. DOI: 10.1016/j.compedu.2005.11.011

Peters, K., 2005. Learning on the move: Mobile technologies in business and education/ flexible learning advisory group. National Library of Australia.

Po-Klin, C., S. Chantachon and S. Wanlu, 2010. The development of community crime preventing network model in northeastern Thailand. J. Soc. Sci., 6: 361-364. DOI: 10.3844/jssp.2010.361.364

Soloway, E., C. Norris, P. Blumenfeld, B. Fishman and J. Krajcik et al., 2001. Handheld devices are readyat-hand. Commun. ACM, 44: 15-20. 